\title{
Depression and aging in dental care
}

\section{Opinion}

Thinking about depression and aging in dentistry, one could highlight that there is usually a misconception that the patient is not willing to take care of his or her own health. However, if one thinks that this condition may also lead the patient to lose interest in life, how can a dentist assess if the person that does not floss or brush his or her teeth correctly is having a negligent behavior? This commentary aims at establishing a few reflections on the specificities that link depression in elderly patients to dental health.

In the literature, a test named Geriatric Depression Scale (GDS) has been widely used as a tool to facilitate the process of refering the patient to proper medical care. ${ }^{1}$ The test has thirty yes or no questions, being very easy and simple to apply right away in the anamnesis or whenever there are any suspitions of the disease. Even though it cannot be used in isolation to diagnose depression in the elderly, it can definitely help the practitioner determine whether additional assessment is needed. ${ }^{2}$

Just like with any other medical issue, depression needs to be tackled and as soons as the dentist is aware of the condition, relevant changes might have to be made in the plan of action. On one hand, many diseases become apparent through an examination of the mouth. For example, stress and anxiety both may cause bruxism, tightening, gritting, and breaking of the teeth, not to mention articular disorders, among others. Such clinical signs and the aforementioned patient's general behavior raise questions whether the disease is present and then the dentist could help in the decision of looking for psychotherapy or psychiatric assistance.

On the other hand, when the patient is already diagnosed with depression, the dentist needs to verify if he or she is in treatment and, the kind of treatment being applied. For instance, if the patient is taking medicines, such as traditional antidepressants, common side effects like xerostomy can be developed, which can interfere in the planning of the treatment. A vast number of elderly patients are complete denture users and retention is one of the most important challenges, especially when dryness of the mouth is a factor. Patients who have their own teeth also need to deal with health issues, such as caries and periodontal diseases. ${ }^{3,4}$

Due to this high susceptibility, the follow-up of these patients may be observed with caution and visits to the clinic should be more
Volume I Issue 2 - 2017

Tania e SP Lacerda

Department of Dentistry, City University of Sao Paulo (UNICID), Brazil

Correspondence: Tania e SP Lacerda, Department of Odontology, City University of Sao Paulo (UNICID), Brazil, Email tanialacerda@col.odo.br

Received: February 02, 2017| Published: March 20, 2017

frequent. When these facts are taken into account while thinking about elderly patients, having a multiprofessional approach is essential. One must remember that these subjects are not solely a mouth that can be treated isolatedly. On the contrary, once the dentist understands the totality of this patient's feelings, emotions, needs, and fisiological conditions, treatment, with the help of other professionals, is always more effective.

\section{Acknowledgements}

None.

\section{Conflict of interest}

Author declares there is no conflict of interest in publishing the article.

\section{References}

1. Yesavage JA, Brink TL, Rose TL, et al. Development and validation of a geriatric depression ranking: a preliminary report. J Psychiatr Res. 1983;17(1):37-49.

2. Barnett JE. Geriatric Depression Scale. In: Vande Creek Leon, editor. USA; 2005.

3. Lacerda TSP. Tecnica de Clonagem Terapeutica em Protese Total. Editora Santos, Brazil; 2015. p. 163-170.

4. Lacerda. Oral Prosthetic Rehabilitation for Alzheimer Patients: Planning, Procedures and Follow-up. J Gerontol Geriatr Res. 2015;4:1-3. 